\title{
A Game Analysis of Outsourcing Strategy for Enterprise Informatization
}

\author{
Zongjian Tang, Geying Liang and Ruxue Wu \\ College of Mathematics and Information Science, Guangxi University, \\ Nanning 530004, P.R. China \\ tang2680@tom.com 1gy2680@163.com wje@gxu.edu.cn
}

\begin{abstract}
Many enterprises adopt outsourcing mode to implement informatization, this is a game process among an informatization enterprise, a software company and an information system. Through analyzing the actions of the three players, we find that, in the informatization process, the participantdegree of an enterprise is in direct proportion to the expected income of the information system, the effort-degree of a software company is in direct proportion to the income of finishing the informatization project. The Nash equilibrium solution of the game is that the enterprise participates passively in the project and the software company works generally. In order to ensure the software company to work hard, there is a compensation item in the contract.
\end{abstract}

Keywords: Information system, Enterprise informatization, Game, Participate, Effort, Outsourcing strategy

\section{INTRODUCTION}

Enterprise informatization outsourcing means that an enterprise will outsource an information system project to a software provider or a system integration provider (we call it as a software company), the software company will develop the information system and put it into service. When an enterprise has signed an informatization outsourcing contract with a software company, the relationship between the two players is called principal-agent relationship which is either a cooperative relation or a competitive relation in the game [1]. They all hope that they pay out the least cost, make the largest profit and succeed in the informatization project. There are many factors affecting the success of an information system, Larsen [2] have divided these factors into 12 categories: IT artifact, IT and support, project, performance, IS maturity, interorganizational relations, structure, task communication, task, individual, MIS department, and environment. In this paper, we apply game theory to analyze actions of an informatization enterprise and a software company in the informatization process, and we hope that it could find a way to improve the success probability of an informatization project. 


\section{A GAME MODEL IN THE INFORMATIZATION PROCESS}

\subsection{A Basic Game Model and Analysis}

In the model, there are three players in the game. They are an informatization enterprise $A_{1}$ (player 1 ), a software company $A_{2}$ (player 2) and an information system to be developed $A_{3}$ (player 3 ). After negotiation, $A_{1}$ and $A 2$ have signed an informatization contract. The contract has been stipulated that $A_{2}$ will construct $A_{3}$ for $A_{1}$, and $A_{1}$ will pay $A_{2}$ the total cost $R$. $A 3$ is passive player. $A_{3}$ will be finished in two feasibility states: The first is that $A_{3}$ will achieve the goals of $A_{1}$, we state its income is 1 . The other is that $A_{3}$ can't achieve the goals, we state its income is 0 . If $A_{2}$ can't achieve the contract objectives, $A_{2}$ will compensate $A_{1}$ for the loss $Q$ and $A_{3}$ is 0.

In the process of implementing informatization, each player can adopt limited pure strategy set $S=\left\{S_{i j} \mid i=1,2,3 ; j=1,2\right\}$. We suppose that $A_{1}$ will adopt two feasibility strategies, that are $S_{1}=\left\{S_{11}, S_{12}\right\}$. Strategy $S_{11}$ is that $A_{1}$ will participate actively in informatization process, reengineer business process, reform organization structure, and allocate full-time persons to cooperate with $A_{2}$. Therefore, $A_{1}$ will expend extra $\operatorname{cost} C_{1}\left(C_{1}>0\right)$. If $\mathrm{A}_{1}$ thinks that it has given $\mathrm{A}_{2}$ payout for the project and $\mathrm{A}_{2}$ will complete all tasks in the project, $A_{1}$ will adopt the passive participation strategy $S_{12}$, then the extra cost $C_{1}=0$. The strategies that $A_{2}$ will adopt have two, $S_{2}=\left\{S_{21}, S_{22}\right\}$. Strategy $S_{21}$ is that $A_{2}$ will appoint the best personnel to implement the project and work hard, so that $A_{2}$ will spend cost $C_{2}$. Strategy $S_{22}$ is that $A_{2}$ hopes that, as soon as possibly, it will pay the lowest $\operatorname{cost} C_{3}$ to complete the project, and obtain $R$ given by $A_{1}$. Comparing with $S_{21}$ and $S_{22}$, we know that $C_{2}>C_{3}>0$. If the project is finished successfully, $A_{3}$ is 1 , the net income of $A_{1}$ in the project is the informatization income $\alpha$ minus various payments, the net income of $A_{2}$ is $R$ minus $C_{2}$ or $C_{3}$. If the project failed, $A_{3}$ is 0 , the net income of $A_{1}$ is $Q$ minus its various payments, the retained profits of $A_{2}$ is $R$ minus the various cost (including Q). According to the analysis, we get an informatization game model listing in Table 1.

Suppose that the success probability of informatization project is $p(0 \leqslant p \leqslant 1)$, and the failure probability is $(1-p)$. The probability of $\mathrm{A}_{1}$ participating actively in the project is $\theta(0 \leqslant \theta \leqslant 1)$, the probability of $A_{1}$ participating passively in the project is (1- $\theta)$. The probability of $A_{2}$ working hard in the project is $\gamma(0 \leqslant \gamma \leqslant 1)$, the probability of $A_{2}$ working generally is $(1-\gamma)$. So the expected net income of $A_{1}$ is, $E\left(\pi_{1}\right)=p\left\{\theta\left[\gamma\left(\alpha-R-C_{1}\right)+(1-\gamma)\left(\alpha-R-C_{1}\right)\right]+(1-\theta)[\gamma(\alpha-R)+(1-\gamma)(\alpha-R)]\right\}$ $+(1-p)\left\{\theta\left[\gamma\left(-R-C_{1}+Q\right)+(1-\gamma)\left(-R-C_{1}+Q\right)\right]+(1-\theta)[\gamma(-R+Q)+(1-\gamma)(-R+Q)]\right\}$ That is $E\left(\pi_{1}\right)=p \alpha-p Q-Q C_{1}-R+Q$ 
Table 1. The Informatization Game Model

\begin{tabular}{|c|c|c|c|c|c|}
\hline \multicolumn{3}{|c|}{ possible strategies } & \multicolumn{3}{c|}{ net income } \\
\hline enterprise $A_{1}$ & $\begin{array}{c}\text { software } \\
\text { company } A_{2}\end{array}$ & $\begin{array}{c}\text { information } \\
\text { system } A_{3}\end{array}$ & $\begin{array}{c}\text { enterprise } \\
\pi_{1}\end{array}$ & $\begin{array}{c}\text { software } \\
\text { company } \pi_{2}\end{array}$ & $\begin{array}{c}\text { information } \\
\text { system }\end{array}$ \\
\hline participate actively & work hard & Success & $\alpha-R-C_{1}$ & $R-C_{2}$ & 1 \\
\hline participate actively & work hard & Failure & $-\mathrm{R}-\mathrm{C}_{1}+\mathrm{Q}$ & $\mathrm{R}-\mathrm{C}_{2}-\mathrm{Q}$ & 0 \\
\hline participate actively & work generally & Success & $\alpha-\mathrm{R}-\mathrm{C}_{1}$ & $\mathrm{R}-\mathrm{C}_{3}$ & 1 \\
\hline participate actively & work generally & failure & $-\mathrm{R}-\mathrm{C}_{1}+\mathrm{Q}$ & $\mathrm{R}-\mathrm{C}_{2}-\mathrm{Q}$ & 0 \\
\hline participate passively & work hard & success & $\alpha-\mathrm{R}$ & $\mathrm{R}-\mathrm{C}_{2}$ & 1 \\
\hline participate passively & work hard & failure & $-\mathrm{R}+\mathrm{Q}$ & $\mathrm{R}-\mathrm{C}_{2}-\mathrm{Q}$ & 0 \\
\hline participate passively & work generally & success & $\alpha-\mathrm{R}$ & $\mathrm{R}-\mathrm{C}_{3}$ & 1 \\
\hline participate passively & work generally & failure & $-\mathrm{R}+\mathrm{Q}$ & $\mathrm{R}-\mathrm{C}_{3}-\mathrm{Q}$ & 0 \\
\hline
\end{tabular}

Suppose the lowest expectation of $\mathrm{A}_{1}$ is no loss in the project, that is $E\left(\pi_{1}\right)=0$, solve equation (1), then

$$
p=\left(\theta C_{1}+R-Q\right) /(\alpha-Q)
$$

If the project is successful, let $p=1$, and then $\theta=(\alpha-R) / C_{1}$. The result shows that, the participant-degree of $A_{1}$ depends on income of $A_{1}$, the larger the expected income is, the more actively $A_{1}$ participate. But it is inverse proportion to the extra cost that $A_{1}$ will pay. That is, if the more transform the enterprise needed to, the less motive $A_{1}$ is to participate in an information project.

The expected income of the software company is

$E\left(\pi_{2}\right)=p\left\{\gamma\left[\theta\left(R-C_{2}\right)+(1-\theta)\left(R-C_{2}\right)\right]+(1-\gamma)\left[\theta\left(R-C_{3}\right)+(1-\theta)\left(R-C_{3}\right)\right]\right\}$ $+(1-p)\left\{\gamma\left[\theta\left(R-C_{2}-Q\right)+(1-\theta)\left(R-C_{2}-Q\right)\right]+(1-\gamma)\left[\theta\left(R-C_{3}-Q\right)+(1-\theta)\left(R-C_{3}-Q\right)\right]\right\}$ That is $E\left(\pi_{2}\right)=p Q-\left(C_{2}-C_{3}\right) \gamma+R-C_{3}-Q$

Suppose the lowest expectation of $\mathrm{A}_{2}$ is no loss in the project, that is $E\left(\pi_{2}\right)=0$, then $p=\left[\left(C_{2}-C_{3}\right) \gamma+\left(Q-R+C_{3}\right)\right] / Q$

If the project is successful, let $\mathrm{p}=1$, then $\gamma=\left(R-C_{3}\right) /\left(C_{2}-C_{3}\right)$. The formula shows that, the effort-degree of $\mathrm{A}_{2}$ is direct proportion to the $\max$ income $R-C_{3}$, is inverse proportion to the extra cost $C_{2}-C_{3}$.

By above analysis, we can see that the success of an informatization project depends on the enterprise payoff.

Differentiate both sides of equation (1)to $\mathrm{p}$ respectively, the result is $\frac{\partial E}{\partial p}=\alpha-Q$. When $\frac{\partial E}{\partial p}=0$, that is $Q=\alpha$, (1) get to extreme number.

If $A_{1}$ wants to ensure the informatization project success, at least without loss, $A_{1}$ should give constraint items on $A_{2}$ in the contract: In order to ensure the income of the informatization investment, $\mathrm{A}_{2}$ should pay compensation $Q$ to $\mathrm{A}_{1}$ for its expected income $\alpha$ if the project failed. This will make $A_{2}$ work hard in the project. 


\subsection{Analyze Strategy in the Game}

\subsubsection{Pure Strategy Solutions in the Game}

Only the informatization enterprise believes the project will succeed, it carries out the project. So we simplify Table 1 into Table 2.

Table 2.The Game Model between an Enterprise and a Software Company

\begin{tabular}{|c|c|c|c|}
\hline & \multicolumn{3}{|c|}{ software company $A_{2}$} \\
\hline \multirow{2}{*}{$\begin{array}{c}\text { informatization } \\
\text { enterprise } A_{1}\end{array}$} & work hard $S_{21}$ & work generally $S_{22}$ \\
\cline { 2 - 5 } & participate Actively $S_{11}$ & $\left(\alpha-R-C_{1}, R-C_{2}\right)$ & $\left(\alpha-R-C_{1}, R-C_{3}\right)$ \\
\hline
\end{tabular}

Because $C_{2}>C_{3}, C_{1}>0$, the Nash equilibrium solution of the game is $(\alpha-R, R-$ $C_{3}$ ). That is, basing on rational consider, $A_{1}$ hopes to gain the most benefit in the project, $A_{1}$ will adopt passive strategy in the project process, $A_{2}$ will implement the project independently. And at the same time, $A_{2}$ will adopt the general program to implement the project. The best strategy of the game is $\left(\mathrm{S}_{12}{ }^{*}, \mathrm{~S}_{22}{ }^{*}\right)$.

In the process of implementing informazation project, if the conditions in $\mathrm{A}_{1}$, such as business process, organization structure, manage manner etc., match with the information system provided by $A_{2}$, what $A_{2}$ will do is to install the software, hardware, and network and turn over the system to the user, the players in the game will not pay extra cost, and the project will be successful. But in the practice, each enterprise that wants to realize informazation has its own characteristic, the software can't match with all enterprises, and the management ideas in the software can't be understood by all enterprises. That is to say, there is asymmetric information in the game. This results in the failure of an informazation project.

\subsubsection{Mixed Strategy Solutions in the Game}

According to above analysis, only in some special cases, the enterprise and the software company adopt Nash equilibrium solution as their optimization strategies in the game. But in many cases this will result in failure of an informazation project. So the players will adopt mixed strategies. The strategies depend on the expected income and extra cost in the informazation project, that is, the participant-degree of an enterprise is $\theta^{*}=(\alpha-R) / C_{1}$, effort-degree of a software company is $\gamma^{*}=\left(R-C_{3}\right) /\left(C_{2}-C_{3}\right)$ 。

\subsubsection{Mixed Strategy Analysis}

Definition 1: An enterprise participant-degree depends on the proportion of expected net income to extra cost in an informazation project. 
The motivation of enterprises implementing an informatization project are diverse, the main motivation is increasing income. So, if the expected net income of the enterprise is little, the impetus that drives an enterprise to participant actively in the informatization project is faint. Suppose the extra cost $C_{1}$ is constant, when $\alpha \rightarrow R, \theta^{*}$ $\rightarrow 0$, an enterprise will adopt passive strategy for cutting down cost in the informatization process. That is, the solution of the game will trend to pure Nash equilibrium strategy.

Definition 2: The software company effort-degree depends on the proportion of the profit to the extra cost in an informazation project.

The main objective that a software company takes part in an informatization project is to develop an information system, promote an enterprise realizing informatization, and make profit in the project. If an enterprise doesn't start up an informatization project, a software company can't gain any benefit. According to above analysis, the software company effort-degree in the informatization process is $\gamma^{*}=\left(R-C_{3}\right) /\left(C_{2}-C_{3}\right)$. Suppose extra cost $C_{2}-C_{3}$ is a constant, when $\mathrm{R}-\mathrm{C}_{3}$ increases, the software company effort-degree will increase. When $R \rightarrow C_{3}$, that is, the income of a software company tends to the basic cost, in order to cut down cost, the software company tends to Nash equilibrium solution from mixed strategy. Although the optimization strategy of the software company is to work generally, if it adopts this strategy, it will take a risk of failure in the project, and will suffer more loss. Therefore, unless the information system provided by the software company matched completely with the enterprise's conditions, the software company will work hard in the project.

\section{CONCLUSIONS}

After we have analyzed the game between an enterprise and a software company in the informatization process, we come to the following conclusions: (1)The actions taken by players in an informatization project have some effects on the success of informatization, but they aren't decisive. (2)An enterprise participant-degree depends on the expected income of the informatization project; the more income is, the more actively the enterprise participate. (3)The software company is important influence on the success of an informatization project. Whether the information system provided by the software company matches with the enterprise conditions is an important factor to the informatization success. (4)The software company effort-degree depends on the profit that it will gain in the informatization project, the more benefit is, the more effort the software company will make. (5)In order to ensure the benefit on informatization investment, the enterprise should list the item in the contract: if the informatization project failed, the software company will pay compensation to the enterprise. The compensation equals the enterprise expected income. This can restrict the actions of the software company, and let it work hard. 


\section{REFERENCES}

1. C. Jiang, Function of Enterprise Informization Supervision and Implementation Method, Digital Manufacturing industry. Volume 12, Number 4, pp.15-16, (2005).

2. Larsen and R.T. Kai, A Taxonomy of Antecedents of Information Systems Success: Variable Analysis Studies, Journal of Management Information Systems. Volume 20, Number 2, pp.169-246, (2003).

3. A.K.P. Wensley and R. Elitzur, Using Game Theory to Analyze Complex Projects: the Case of Information System Outsourcing Arrangements, International Journal of Industrial Engineering: Theory Applications and Practice. Volume 6, Number 2, pp.141150, (1999).

4. D. Fudenberg and J. Tirole, Game Theory (MIT Press: Cambridge, MA, 1991). 